\title{
O PROCESSO DE CONSTRUÇÃO DO PROJETO PEDAGÓGICO: PLANEJAMENTO E AÇÁO
}

\author{
Prof. a Dr. ${ }^{\text {a }}$ Maria Lourdes GISI* \\ Prof. ${ }^{a}$ Maria Leda VIEIRA* \\ Prof. ${ }^{\text {E Ézia Maria CORRADI }}{ }^{* * *}$ \\ Prof. ${ }^{a}$ Marilin HOHL
}

Resumo

Este relato de experiência refere-se ao processo de construção do Projeto Pedagógico do Curso de Enfermagem da Pontifícia Universidade Católica do Paraná - PUCPR. No início de 1998, a PUCPR desencadeou um amplo processo de avaliação das práticas pedagógicas, no âmbito da Instituição, com o intuito de instrumentalizar os Cursos na construção dos seus projetos pedagógicos. A partir dessa avaliação, com participação de docentes e discentes, mediante reflexão coletiva, iniciou-se a construção do Projeto Pedagógico do Curso de Enfermagem com o objetivo de favorecer a melhoria da qualidade do ensino da graduação. Compreendido como um instrumento norteador da ação docente, o projeto primou pelas seguintes dimensões: dimensão conceitual, dimensão estrutural: eixo norteador; eixos temáticos, aptidões/competências, programas de aprendizagem e projetos integrados. dimensão metodológica e dimensão operacional. Esta última refere-se as metas para a consecução da proposta: qualificação do corpo docente; recursos físicos e materiais; reavaliação dos campos de estágio; organização de grupos de pesquisa; desenvolvimento de projetos de extensão e sistemática da avaliação e acompanhamento da proposta. O projeto, implantado no início de 2000, tem evidenciado uma prática pedagógica inovadora, além da participação ativa dos alunos no seu processo de aprendizagem.

Palavras-chave: Enfermagem, Projeto Pedagógico, Currículo.

\section{Resumen}

Este relato de experiencia se refiere al proceso de elaboración del Projecto Pedagógico del Curso de Enfermería de la Universidad Pontificia Católica del Paraná - PUCPR.

Al inicio de 1998, la PUCPR comenzó um amplio proceso de evaluación de las prácticas pedagógicas en el ámbito de la Institución con la finalidad de instrumentalizar los cursos en la elaboración de sus projectos pedagógicos. A partir de esa evaluación, con participación de profesores y alumnos, mediante una reflexión colectiva, se inició la elaboración del Projecto Pedagógico del Curso de Enfermería con el objetivo de favorecer la mejora de calidad de la enseñanza en el ámbito de la graduación (primer grado).

Considerado como un instrumento orientador de la acción docente, el projecto priorizó las seguintes dimensiones: dimensión conceptual, dimensión estructural como eje orientador, ejes temáticos, aptitudes y competencias, programas de aprendizado y projectos integrados, dimensión metodológica y dimensión operacional. Esta última se refiere a las metas para conseguir la propuesta: calificación del cuerpo docente, recursos físicos y materiales, re-evaluación de los lugares de prácticas, organización de grupos de investigación, desarmollo de projectos de extensión y sistema de evaluación y acompañamiento de la propuesta.

El projecto, implantado al inicio del 2000, ha demostrado ser una práctica pedagógica innovadora además de incluir la participación activa de los alumnos durante el proceso de aprendizaje.

Palabras llave: enfermería, projecto pedagógico, currículo.

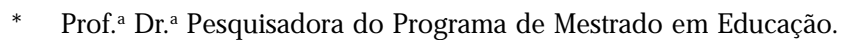

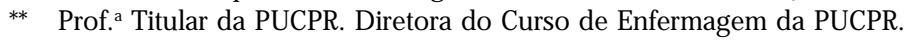

*** Prof. ${ }^{\text {a }}$ Ms. da PUCPR.

* ${ }^{*} *$ Prof. ${ }^{\text {a }}$ Ms. da PUCPR. 


\section{Introdução}

Este trabalho tem como objetivo relatar a experiência de construção do Projeto Pedagógico do Curso de Enfermagem da Pontifícia Universidade Católica do Paraná - PUCPR. Criado em 1954 e reconhecido em 1957 com o nome de Curso de Enfermagem Madre Leonie foi submetido a reformulações curriculares em atendimento às exigências estabelecidas nos Currículos Mínimos Nacionais (Parecer no 271/62, Parecer n.․ 163/72-CFE e Portaria n... 1721/94-MEC). Nesta última, foram levados em consideração, também, os documentos oriundos das Conferências Nacionais de Saúde e a Lei Orgânica de Saúde - Lei oㅡ 8080/90 (SANTOS et al.,1997; BRASIL, 1994; CARVALHO; SANTOS, 1995).

A partir de 1998, em decorrência de diretrizes internas da PUCPR, o Curso de Enfermagem iniciou a construção do seu projeto pedagógico que começou a ser implantado no primeiro semestre de 2000.

Esta nova proposta pedagógica resulta de um esforço coletivo voltado para a superação de práticas fragmentárias, decorrentes de abordagens que dicotomizam teoria e prática, conhecimento geral e específico, dimensão técnica e humana que, por sua vez, reforçam outras dicotomias que ainda hoje se fazem presentes na área da saúde, tais como: saúde individual e coletiva, assistência preventiva e curativa.

É nesta perspectiva que a proposta busca ultrapassar a organização curricular por disciplinas estanques e fechadas no entendimento de que: "É na unidade da dinâmica curricular que ganham forma as diversas áreas do saber, não no soberbo isolamento delas e, muito menos no enclausuramento em disciplinas que compartimentam os conhecimentos ..." (MARQUES, 1999, p.18).

Elaborar uma proposta pedagógica, pautada na busca da integração das diferentes dimensões do saber/fazer profissional, pressupõe compreender que os conhecimentos específicos que são trabalhados em diferentes situações de aprendizagem somente adquirem esclarecimento e sentido ao se inserirem no " $\{. .$.$\} universo amplo do que se aprende a partir do mundo da vida$ em seu processo de produção coletiva ancorada nas tradições históricas e nos projetos de futuro" (MARQUES, 1999, p.18).

Uma proposta pedagógica, na qual a interação se constitua em processo de superação de práticas vigentes, pressupõe professores comprometidos com um novo saber/fazer pedagógico que engloba: a compreensão da complexidade da realidade social e dos determinantes históricos da profissão; o domínio do referencial teórico-instrumental da prática da enfermagem e de referencial pedagógico para uma nova prática pedagógica.

É somente com tais saberes que os professores estarão em condições de definir as aptidões ${ }^{4}$ e competências ${ }^{5}$ a serem contempladas no processo de formação e, posteriormente, organizar as condições necessárias para a aprendizagem dos alunos. 
A partir de aptidões/competências é que são organizados os programas de aprendizagem ${ }^{6}$ com conhecimentos oriundos de diferentes disciplinas, para articular, de forma dinâmica, teoria/prática e ensino/trabalho. Com isso, o que se busca é aprendizagens relevantes para uma sociedade em ritmo acelerado de mudanças.

Sabe-se que esta tarefa é complexa, pois requer a reconstrução de uma prática pedagógica calcada em bases conservadoras. Um processo que não se dá num passe de mágica e, por isso mesmo, deve constituir-se em construção progressiva, de aproximações sucessivas de modo a tornar realidade o que foi concebido pelo grupo como a sua utopia.

A busca da superação de tais práticas não é fato novo para a Enfermagem brasileira. Nas últimas décadas, o ensino da enfermagem vem sendo questionado, principalmente, porque a prática pedagógica predominante continua sendo aquela de características conservadoras, enfocada na ação dos docentes e na abordagem da pedagogia tradicional. Essa pedagogia adotada e praticada pelos professores não proporciona ao estudante as condições necessárias para uma formação condizente com os novos tempos. Hoje destaca-se a capacidade de aprender a aprender comprometida com o questionamento crítico da realidade na busca da transformação da sociedade em que se vive e se atua.

Sabe-se que a maioria dos docentes de enfermagem não estão suficientemente preparados para desenvolver nos educandos a consciência crítica e reflexiva, uma vez que também não tiveram essa formação. Entretanto, em pesquisa desenvolvida por SAUPE (1993), foram comprovadas mudanças com relação ao ensino de Enfermagem. Há uma expressão já significativa de educadores críticos que se opõem aos modelos rígidos e tradicionais e buscam desenvolver uma prática pedagógica democrática e participativa no entendimento de que a enfermagem é uma profissão historicamente determinada, numa sociedade em constante transformação.

LIMA \& CASSIANI (2000) enfatizam que o ensino da Enfermagem, desde sua institucionalização, vem, paulatinamente, passando por várias transformações na busca da competência profissional, procurando acompanhar o desenvolvimento técnico-científico necessário para sua atuação. É importante ressaltar, também, que a Enfermagem brasileira, mais especificamente a partir de 1980, começa a pautar-se em referenciais teórico-críticos, compreendendo a profissão como prática social sujeita as determinações sócio-políticas, econômicas e culturais da sociedade.

Hoje, no entanto, o ensino de enfermagem enfrenta um novo desafio: preparar enfermeiras e enfermeiros que possam responder às rápidas transformações no setor saúde e na sociedade como um todo. Tais transformações requerem mudanças da educação superior para que esta possa ocupar seu espaço no desenvolvimento cultural e sócio-econômico comprometido com a 
promoção da igualdade social. Significa estar voltado ao mesmo tempo para o desenvolvimento tecnológico e para a promoção da cidadania. Portanto, comprometido com a produção do saber que atenda os interesses sociais mais amplos (Plano Nacional de Graduação, 1999).

Para tanto, necessita-se formar profissionais que possam ser capazes de pensar e agir crítica e reflexivamente; saber observar e interpretar a realidade; tomar decisões; planejar as ações necessárias, e, ainda, capazes de gerenciar, com competência, o processo de trabalho em saúde/ enfermagem em todos os âmbitos de atuação profissional; atuar em equipes multiprofissionais de saúde; aprender a aprender de forma contínua, tornando-se um agente da ação transformadora e capazes de fazer a leitura do mundo em que vivem.

Estas reflexões, segundo PETTENGIL et al. (1998, p. 25), "significam repensar o ato de ensinar enquanto ato pedagógico, ou seja, ato que tem um sentido ético-político, um sentido epistemológico diante do conhecimento e um sentido relacional de interação entre subjetividades distintas". Pode-se acrescentar que este ato pedagógico não pode ser resultado, tão somente, de um esforço individual, mas decorrente de um processo de reflexão coletiva e assumido de forma explícita no projeto pedagógico do curso.

Falar em projeto significa falar na possibilidade de construir o novo. Significa falar de uma ação voltada para criar uma realidade futura. Em se tratando de uma projeto político-pedagógico, esta ação é intencional, tem sentido explícito e compromisso definido coletivamente. "É político porque expressa um compromisso com a formação do cidadão para um tipo de sociedade e é pedagógico ao definir as ações educativas e as características necessárias para o cumprimento dos seus propósitos e sua intencionalidade" (VEIGA, 1996, p.13).

O projeto busca um rumo, uma direção, é construído e vivenciado em todos os momentos, por todos os envolvidos com o processo educativo. É, também, um projeto político por estar intimamente articulado aos interesses reais e coletivos da população.

Podemos considerar um projeto político-pedagógico como um “\{...\} conjunto de diretrizes e estratégias que expressam e orientam a prática pedagógica do curso". Com essa concepção, este não pode ser confundido com 0 currículo. A sua abrangência vai além, trata-se da própria concepção do curso, do processo de formação de um certo profissional em momento histórico determinado (SILVA IN: GISI \& ZAINKO, 1998 p.42).

Compreender o projeto político-pedagógico como um instrumento orientador do processo educativo, isto é, do processo de ação-reflexão-ação, pressupõe superar a idéia de um documento elaborado a priori como um plano rígido a ser seguido. Deve, sim, ser um " $\{. .$.$\} indicador de rumos que$ favorece a análise dos resultados do esforço coletivo para uma educação emancipadora" (GISI, 2000, p.35). 
O projeto pedagógico da PUCPR vem se constituindo em estratégia de reflexão contínua, permitindo avaliar cada etapa e desta forma retomar ou reorientar os rumos definidos inicialmente

\section{0 processo de construção da proposta}

O Projeto Pedagógico do Curso de Enfermagem da PUCPR, resultado de construção coletiva, articula meios e fins, explicitando a finalidade do processo educativo, as ações pedagógicas e os procedimentos de acompanhamento e implantação da proposta. Constitui parte integrante do Projeto Institucional que mediante planejamento estratégico estabeleceu metas a serem alcançadas pela Instituição e, portanto, pelos Cursos que oferta.

O planejamento estratégico definiu como centro de suas atenções a "graduação" e esta definição mobilizou a comunidade universitária em torno da questão pedagógica. Como afirma DIAS SOBRINHO: “A questão pedagógica é a dimensão mais universal e permanente da universidade, por meio da qual esta instituição se distingue das outras ..." e "[...] ao assumir claramente esta dimensão, cria as condições para o amplo desenvolvimento dos seus processos sociais e políticos" (2000, p.32-3).

Para dinamizar este trabalho, na Instituição, foram constituídas Comissões de Sistematização compostas por professores dos cursos, responsáveis pela coordenação do processo e Comissões de Apoio Pedagógico compostas por professores da Área de Educação para assessorar os professores de cada curso.

Concomitante ao processo de construção da proposta nos cursos, a Instituição, por meio da Pró-Reitoria Acadêmica, organizou vários eventos em forma de oficinas e conferências sobre temas como:

- Currículo - perspectivas e possibilidades à luz da construção do projeto pedagógico do ensino superior.

- Metodologias inovadoras - tecnologia educacional, ensino com pesquisa e Problem Basic Learning (PBL).

- Avaliação da aprendizagem no ensino superior.

Tais iniciativas, por parte da Instituição, prepararam um cenário propício para o repensar do processo pedagógico vigente e a proposição de novas práticas.

A Comissão de Sistematização do Curso de Enfermagem, com o intuito de favorecer a participação dos envolvidos com o ensino de graduação em Enfermagem, organizou reuniões com o corpo docente e representantes discentes para cada etapa de construção da proposta. Nessas reuniões, foi possí- 
vel: discutir os encaminhamentos necessários, construir conceitos, analisar proposições, realizar estudos e construir os programas de aprendizagem.

Os documentos de apoio utilizados neste trabalho foram: O relatório do 3o e 4을 SENADEn (ABEn, 1998 e 2000), a proposta de diretrizes curriculares-SESU/MEC; a Lei do Exercício Profissional (SANTOS et al., 1997) e Currículos de Cursos de Enfermagem de outras Universidades.

O processo de construção do Projeto Pedagógico do Curso de Enfermagem deu-se em duas fases. A primeira fase, realizada em 1998, refere-se ao diagnóstico do Curso, o qual permitiu caracterizar a população educacional, as demandas e necessidades sociais e de mercado, as necessidades de infra-estrutura, de convênios, projetos especiais e a proposição de um plano de qualificação do corpo docente. Permitiu, ainda, obter uma avaliação do Curso pelos egressos. A partir destes dados, o grupo propôs o perfil e as competências a serem desenvolvidas pelos alunos e as competências (específicas da área e as pedagógicas) do professor para propiciar o desenvolvimento das competências propostas para os alunos.

A segunda fase, realizada em 1999, refere-se a elaboração da proposta. Como primeira atividade, discutiu-se o diagnóstico do Curso com o objetivo de validar os dados ou modificá-los ou ainda acrescentar aspectos não contemplados. Neste momento, foi fundamental a presença dos alunos para avaliarem as disciplinas que estavam cursando ou que já haviam cursado.

A partir desta discussão inicial sobre o diagnóstico e do Seminário sobre Currículo Integrado em Enfermagem, deu-se início à construção da concepção do curso. Inicialmente, foi apresentado um panorama da realidade global, indicando os desafios existentes para formação profissional na atualidade e, na seqüência, mediante dinâmicas de grupo, foram construídos os conceitos de educação, saúde, enfermagem, cuidado de enfermagem, processo educativo e a concepção da metodologia e da avaliação da aprendizagem, expressando a utopia do grupo, como indica GANDIN (1994).

Com base nesta dimensão conceitual foi concebida a dimensão estrutural do curso para a qual foram definidos: eixo norteador e eixos temáticos ${ }^{7}$, programas de aprendizagem e projetos integrados ${ }^{8}$.

\section{A proposta pedagógica}

\subsection{Dimensão conceitual}

\subsubsection{Concepção do curso}

O Curso de Enfermagem da PUCPR tem como finalidade propiciar sólida formação geral e humanista, incorporando as dimensões técnica, científico-profissional, ético-político-social, educativa e de liderança. 
A partir destas dimensões, busca oportunizar o desenvolvimento de aptidões para atuar nos diferentes cenários da prática profissional, na assistência à saúde do indivíduo, família e comunidade em todas as fases evolutivas do ser humano.

De acordo com a Constituição Federal, "Saúde é direito de todos e dever do Estado, garantida mediante políticas sociais e econômicas que visem a redução do risco de doenças e outros agravos e ao acesso universal e igualitário às ações e serviços para a sua promoção, proteção e recuperação" (Brasil, 1988).

Embora assegurado no plano jurídico, a sua concretização ainda se encontra distante da realidade vivenciada, mas é com este direito que os profissionais da saúde devem estar comprometidos. Como indica GARCIA (1989, p.103) "Saúde é definida como o máximo desenvolvimento das potencialidades do homem, de acordo com o grau de avanço obtido pela sociedade em um período histórico determinado". Significa que saúde precisa ser concebida como resultante das reais condições de existência, pensada coletivamente e não apenas do ponto de vista individual e ser entendida como potencializadora do ser humano no seu desenvolvimento integral.

No contexto da área da saúde, o enfermeiro e a enfermeira ocupam papel de fundamental importância como agentes do processo de trabalho em saúde, atuando em equipes multiprofissionais com responsabilidade ética e social. Desenvolvem uma prática comprometida com a promoção, manutenção e restauração da saúde mediante o cuidar profissional (individual e coletivo) e buscam também, tornar o outro capaz de cuidar-se (empoderamento), respeitando a individualidade (cultura e crenças), integrando técnica e humanismo.

O cuidado de enfermagem é considerado a essência do seu saber/ fazer. É entendido como um cuidado profissional que se realiza mediante 0 desenvolvimento de ações baseadas em conhecimentos técnico-científicos e em atitudes éticas e humanísticas. É um cuidado holístico que pressupõe compreender o ser humano, interagir com ele, desenvolvendo uma experiência compartilhada.

Educar para o cuidar em enfermagem significa compreender a educação como processo de desenvolvimento do ser humano, propiciando ao aluno espaço para que se torne sujeito da própria educação, além de criar-lhe condições para desenvolver reflexão crítica e se comprometer com a transformação da sociedade em que vive e atua. Significa que no processo educativo, os programas de aprendizagem/projetos integrados e os seus métodos devem estar voltados para a sua finalidade: formar em termos de cidadania e profissionalização com capacidade para: 
- Identificar as necessidades individuais e coletivas de saúde da população, seus condicionamentos e determinantes, considerando os pressupostos dos modelos clínico e epidemiológico.

- Intervir no processo de saúde/doença com responsabilidade pela qualidade da assistência/cuidado ao ser humano nos diferentes níveis de atuação, na perspectiva da integralidade da assistência.

- Prestar cuidados de enfermagem compatíveis com as diferentes necessidades apresentadas pelos indivíduos, família e comunidade em todas etapas do ciclo vital.

- Gerenciar o trabalho da enfermagem em todos os âmbitos de atuação profissional com competência técnico-científica, com sensibilidade ética e compromisso com a democratização das relações sociais.

- Desenvolver programas de educação/promoção à saúde para os diferentes grupos sociais e distintos processos de vida, saúde, trabalho e adoecimento, respeitando os diferentes estilos de vida em saúde.

- Desenvolver programas de educação contínua dos trabalhadores de saúde/enfermagem, mediante um trabalho pedagógico pautado na interdisciplinaridade e na vivência da prática profissional.

- Produzir conhecimento na área da enfermagem que objetive a qualificação da prática profissional e contribua com a qualidade de vida da população.

\subsection{Dimensão estrutural}

Estabeleceu-se como eixo norteador o cuidado de enfermagem que se desdobra em eixos temáticos num total de cinco. O primeiro, corresponde ao processo saúde/doença, que se constitui no fenômeno com o qual os alunos irão se defrontar na sua vida profissional; o segundo, terceiro e quarto eixo, referem-se ao cuidado de enfermagem, que representa a especificidade da prática profissional. É mediante o cuidado profissional que a enfermagem atua no processo saúde/doença; o quinto e último eixo, referem-se ao processo de administrar, que tem como objetivo criar as condições necessárias para realizar um cuidado de enfermagem de qualidade. Cada eixo temático por sua 
vez comporta aptidões, competências e habilidades intermediárias, originando os programas de aprendizagem e projetos integrados (figura 1).

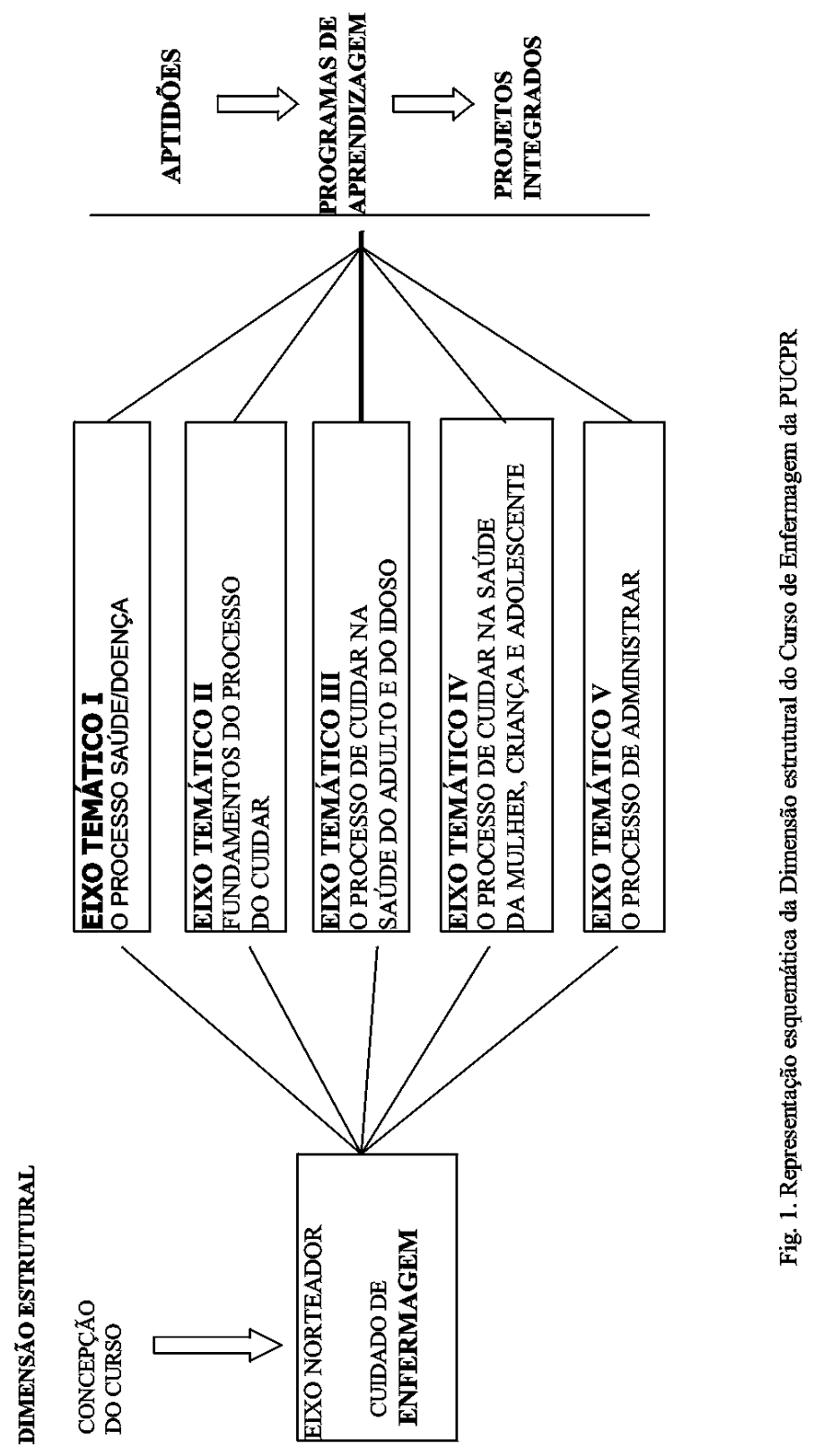




\subsection{Dimensã o metodológica}

Num mundo caracterizado por contínuas mudanças, em que os conhecimentos tornam-se, rapidamente, ultrapassados, faz-se necessária uma abordagem metodológica que possibilite o contínuo aprender. Isto requer 0 desenvolvimento do espírito investigativo e a capacidade de propor soluções criativas para as diferentes situações com as quais o profissional irá se defrontar na sua prática cotidiana.

Uma metodologia em que o aluno tenha condições de se apropriar da construção histórica do conhecimento, que seja instrumentalizado para a sua construção crítica e capacitado para detectar problemas na busca de soluções criativas.

Nesta perspectiva, optou-se por adotar uma metodologia baseada na pedagogia da problematização e no ensino com pesquisa.

Esta metodologia busca desenvolver a capacidade de observar a realidade do ponto de vista global e estrutural, identificar os problemas, detectar os recursos existentes, e, mediante suporte teórico, formular hipóteses de solução e formas de intervenção na realidade observada. Como afirma BORDENAVE \& PEREIRA (1982) a aprendizagem torna-se uma pesquisa e a construção do conhecimento se dá em estreita relação com a realidade. Assim, o ensino com pesquisa insere-se nesta proposta metodológica, permeando todo o processo. Tal opção implica em considerar, como indica DEMO (1997), a pesquisa como atitude cotidiana ao cultivar a consciência crítica e como resultado específico ao intervir na realidade com base na capacidade questionadora; um compromisso formal com a reconstrução do conhecimento. A pedagogia da problematização coloca-se como uma proposta coerente com este propósito o que é melhor compreendido a partir do seu método:

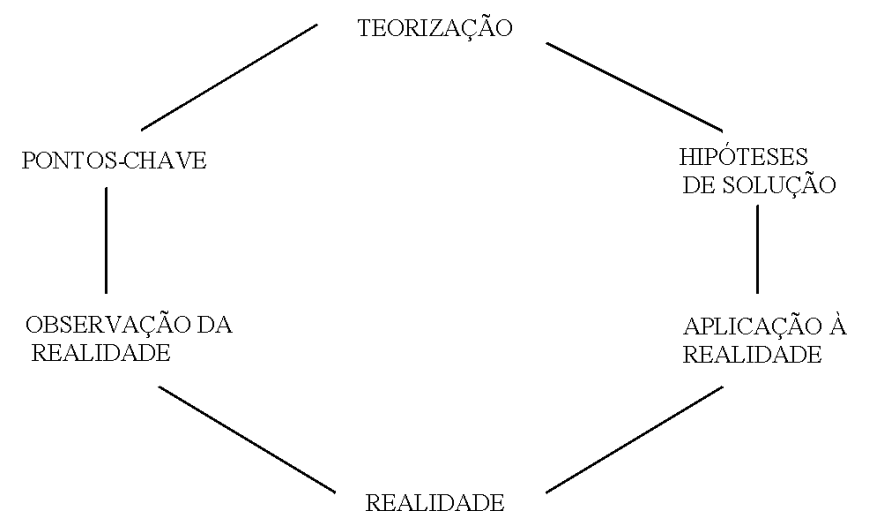

Fig. 2. Método do Arco de Maguerez in: Bordenave \& Pereira, 1982. 
O aluno é levado a observar uma realidade relacionada à temática do programa de aprendizagem e dos projetos integrados que está cursando. Neste momento, busca-se desenvolver a capacidade de identificar os aspectos de maior relevância presentes na realidade, e os problemas ali existentes. Dos problemas identificados, serão eleitos aqueles que serão foco de atenção do estudo com base nos seguintes critérios: relevância, factibilidade, interesse para aprendizagem e os que requerem soluções imediatas. Após esta etapa, serão elencados os pontos-chave dos problemas selecionados, identificando sua natureza (econômica, cultural, de educação etc.), os seus determinantes mais amplos, bem como suas conseqüências para determinada realidade social. Esta fase orienta a teorização, que por sua vez, deve possibilitar a análise das diferentes dimensões dos problemas detectados. É a partir da teorização que são formuladas as hipóteses de solução, as quais devem ser confrontadas com as discussões iniciais com o objetivo de validar as percepções existentes, anteriormente, e as contribuições da teorização. Após esta fase, dá-se a intervenção na realidade que implica em compromisso social com a realidade objeto do estudo ${ }^{9}$. 0 processo se constitui em ação-reflexão-ação e em uma aprendizagem significativa porque situada, contextualizada e apresentada como um desafio para os alunos. Conforme indica PERRENOUD "Um problema deve estar de alguma maneira incluído em uma situação que lhe dê sentido" (1999, p.57). Os problemas não devem ser artificiais e descontextualizados, pois, não propiciam uma aprendizagem significativa.

As atividades de aprendizagem previstas são variadas e contemplam: leitura de textos, seminários, aulas expositivas dialogadas, grupos de discussão, grupos operativos para análise do trabalho de campo, atividades práticas de laboratório e de campo, estágios em hospitais e unidades de saúde, e outros além de pesquisa bibliográfica e de campo. Tudo isso busca propiciar espaço para que o aluno possa observar, formular perguntas, expressar suas percepções, desenvolvendo atividades ligadas a aspectos significativos da realidade, possibilitando, desta forma, que sejam contemplados no processo de formação a capacidade de observação, análise, avaliação, compreensão, aplicação e atitudes de cooperação e de respeito pelo outro.

O professor estabelece com os alunos uma relação em que prevalece o diálogo voltado para a compreensão e a reflexão crítica da realidade.

A avaliação da aprendizagem é entendida como processo que acompanha o desenvolvimento das aptidões/competências e habilidades previstas. Busca ultrapassar a avaliação reprodutivista, pois a memorização não constitui o objetivo deste processo educativo, ao contrário, valoriza-se a construção do conhecimento e a capacidade de análise e reflexão do aluno. Assim, a avaliação é compreendida como atividade indissociável do processo educativo, levando-se em consideração as diferentes formas de produção dos alunos, em diferentes contextos e com caráter formativo. 
Uma forma bastante eficaz de avaliação é aquela em que o aluno é confrontado com uma situação nova na qual utilizará conhecimentos já trabalhados em momentos anteriores. Conforme indica MERIEU:

... é necessário praticar a avaliação como descontextualização sistemática e meio de identificar aquisições. Descontextualizar é utilizar um conhecimento em outra situação, numa ruptura em relação à situação de aquisição, com outros exemplos, dentro de outro quadro, dentro de outro contexto intelectual mas também sócio-cognitivo ou até mesmo com outras pessoas; identificar as aquisições significa saber nomeá-las, exteriorizá-las ser capaz de colocá-las em prova, sobretudo, à prova do tempo (1998, p.99).

Na pedagogia da problematização, os discentes se defrontam continuamente com novas situações de aprendizagem, o que permite avaliar as aptidões, competências, habilidades que se referem a uma ação eficaz, realizada em diferentes contextos de aprendizagem .

\subsection{Dimensão operacional}

etapas:

Para a operacionalização da proposta, foram definidas as seguintes

- Definição de coordenadores (docente de enfermagem) por período do curso, com responsabilidade de organizar o planejamento, a avaliação dos programas e a articulação entre os programas e projetos integrados do período.

- Capacitação pedagógica dos professores do Curso.

- Articulação com os serviços de saúde que se constituem em campo de prática/ estágio e a reavaliação dos campos de estágio.

- Organização de grupos de pesquisa.

- Desenvolvimento de projetos de extensão.

- Valorização de atividades acadêmicas tais como: iniciação científica, semana acadêmica, participação em projetos de pesquisa, de extensão e estágios voluntários e participação em eventos científicos e culturais.

- Aquisição de materiais e equipamentos para o laboratório de enfermagem.

- Qualificação do corpo docente.

- Acompanhamento e avaliação do projeto pedagógico mediante:

1- Reuniões semanais dos docentes que atuam num mesmo programa de aprendizagem.

2- Reuniões mensais dos docentes que atuam num mesmo período do curso. 
3- Reuniões semanais da comissão de sistematização com participação dos coordenadores dos períodos.

4- Reuniões, em final de semestre, dos professores que atuaram num período com os professores que irão atuar no período seguinte.

5- Aplicação de questionários junto aos alunos e professores.

\section{Considerações finais}

A construção de um projeto pedagógico exige esforço conjunto de todos os envolvidos na prática educativa do Curso. Para isto, faz-se necessário propiciar espaço para estudos, reflexões para que a proposta construída seja coerente e assumida por todos.

É preciso, ainda, ter clareza de que um projeto não pode constituir-se jamais em um documento acabado, mas deverá estar sempre em construção, contemplando as transformações que se fizerem necessárias. Neste sentido, a avaliação deverá ser compreendida como parte integrante do projeto, pois é a partir da avaliação contínua que se torna possível identificar problemas existentes e propor formas de solução.

Esta não é uma tarefa fácil, pois para que uma proposta se efetive, há necessidade, principalmente, de mudança da prática pedagógica 0 que depende de professores abertos a mudanças e formação pedagógica condizente com o que se propõe realizar. Cabe à instituição oportunizar esta formação, se almeja uma aprendizagem de qualidade para seus alunos.

Os professores do Curso de Enfermagem da PUCPR têm participado de várias oficinas pedagógicas, curso de capacitação pedagógica, reuniões de discussão e análise da proposta. Assim, mesmo, entende-se que este é um processo que se inicia e que requer contínuo aprofundamento em estudos que possam subsidiar o trabalho pedagógico necessário para a atualidade.

Todo processo de mudança gera incertezas. Quando não há uma sistemática de estudos para o aprofundamento teórico e condições de trabalho favoráveis para operacionalizar as propostas, corre-se o risco de retornar a velhas formas de ensinar, não se propiciando a mudança desejada. Isto demanda um esforço coletivo para superação dos limites existentes.

Embora cientes de que ainda há muito para construir, pode-se afirmar que um grande passo foi dado. Os professores não trabalham mais isoladamente, os programas de aprendizagem são construídos coletivamente e desenvolvidos por dois, três ou quatro professores, em conjun- 
to, buscando uma efetiva integração de conhecimentos. Os alunos entendem que há um direcionamento metodológico não por parte de um professor, mas de todo corpo docente, o que favorece maior aceitação e participação, nesse contexto.

\section{Notas bibliográficas}

4 APTIDÃO, significa capacidade que deve ser desenvolvida para atuar em relação às circunstâncias da vida (BOTOMÉ, 2000).

5 COMPETÊNCIA, representa uma aptidão desenvolvida gerando independência, segurança e precisão (BOTOMÉ, 2000). É a capacidade de agir eficazmente em um determinado tipo de situação, apoiada em conhecimentos, mas sem limitar-se a eles (PERRENOUD, 1999). Seu foco não está num desempenho avaliável do adquirinte, mas em procedimentos internos ao adquirinte (cognitivos, lingüísticos, afetivos, motivacionais) (BERNSTEIN, 1996, p.104).

6 É a unidade de trabalho organizada para compor a aprendizagem dos alunos a partir das aptidões e competências necessárias para quem vai atuar em determinada situação social (BOTOMÉ, 2000).

7 O eixo norteador representa a referência, o foco central, do ensino da enfermagem. A partir deste eixo, foram definidos os eixos temáticos que têm como finalidade imprimir uma direção na organização e desenvolvimento dos programas de aprendizagem e dos projetos integrados bem como favorecer a integração dos conhecimentos a serem trabalhados.

8 É a unidade de trabalho organizada sob a forma de estágio supervisionado associado à pesquisa. Tem como base os conhecimentos trabalhados nos programas de aprendizagem, definidos em cada eixo temático.

9 A fase que corresponde a intervenção na realidade só ocorre nos programas de aprendizagem que contemplam atividades de campo relativas aos estágios, pesquisas e projetos integrados.

\section{Referências bibliográficas}

ASSOCIAÇÃO BRASILEIRA DE ENFERMAGEM - ABEn. Relatório final do 3o Seminário nacional de Diretrizes para a Educação em Enfermagem no Brasil

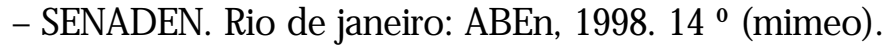

Relatório final do 4⿳一 Seminário Nacional de Diretrizes para a Educação em Enfermagem no Brasil.- SENADEN. Fortaleza: ABEn, 2000. 10 p. (mimeo).

BAIZAN, Newton César; DIAS SOBRINHO,José. Avaliação institucional: teoria e experiências. 2ed. São Paulo: Cortez, 2000.

BERNSTEIN, Basil. A estruturação do discurso pedagógico: classe, códigos e controle. Petrópolis: Vozes, 1996. 
BRASIL Portaria no 1721, 15 dez. 1994. Dispõe sobre a formação do enfermeiro de Graduação e revoga Resolução no 4 de 25 de fevereiro. 1972. Diánio Oficial (Brasilia), nํ 238, no 19801, 1994. Seção 1.

BRASIL Constituição da República Federativa do Brasil. Manual de legislação. 7 ed. São Paulo: Atlas, 1996. 228 p.

BORDENAVE, Juan Diaz; PEREIRA, Adair Martins. Estratégias de ensino aprendizagem. 6. ed. Campinas: Autores Associados, 1997.

BOTOMÉ, Silvio Paulo. Diretrizes para o ensino de graduação: O projeto pedagógico da Pontifícia Universidade Católica do Paraná, Curitiba: Champagnat, 2000.

CARVALHO, G.I.; SANTOS, L Comentários à Lei Orgânica de Saúde (Lei no 8080/90 e 8.140/90) Sistema Único de Saúde. 2. ed. São Paulo: Hucitec. 394p.

DAVINI, Maria Cristina. Currículo integrado. In: BRASIL Ministério da Saúde. Secretaria Executiva. Coordenação Geral de Desenvolvimento de Recursos Humanos para o SUS. Capacitação pedagógica para o instrutor/supervisor - área da saúde. Brasília: Ministério da Saúde, 1994. P. 39-48.

DEMO, Pedro. Educar pela pesquisa. 2.ed. Campinas: Autores Associados, 1997. FÓRUM DE PRÓ-REITORES DE GRADUAÇÃO das Universidades Braileiras. Plano Nacional de Graduação: um projeto em construção. Rio de Janeiro, 1999 (mimeo).

GISI, Maria Lourdes. Teoria e prática do currículo. Curitiba: PUCPR/CIVITAS/ SEDP, 2000.

GISI, Maria Lourdes; ZAINKO, Maria Amélia Sabbag. Universidade e construção do projeto político-pedagógico dos cursos. In: SAUPE, Rosita (Org.). Educação em enfermagem: da realidade construída à possibilidade em construção. Florianópolis: UFSC, 1998. Cap. 3, p. 87-118.

LIMA, Maria Auxiliadora da Cruz; CASSIANI, Silvia Helena De Bortoli. Pensamento crítico: um enfoque na educação de enfermagem. Revista Latino-Americana Enfermagem, Ribeirão Preto, v. 8, n. 1, p. 23-30, jan. 2000.

MARQUES, Mário Osório. A dinâmica de um curnículo integrado. In: Currículo escolar: propósitos e práticas. Santa Cruz do Sul: EDUNISC, 1999.

MERIEU, Philippe. Aprender...sim, mas como? 7.ed. Porto Alegre: Artes Médicas, 1998.

PERRENOUD, Philippe. Construir as competências desde a escola. Porto Alegre: Artes Médicas Sul, 1999. 
PETTENGIL, Myriam A. Mandella et al. O professor de enfermagem frente às tendências pedagógicas. Uma breve reflexão. Revista da Escola de Enfermagem da USP, v. 32, n. 1, p. 16-26, abr. 1998.

SANTOS, Elaine Franco et al. Legislação em enfermagem: atos normativos do exercício e do ensino da enfermagem. São Paulo: Atheneu, 1997.

SAUPE, Rosita. O professor de enfermagem - a transformação possível. Revista da Escola de Enfermagem da USP, São Paulo, v. 27, n. 1, p. 151-160, abr. 1993. VeIGA, Ilma Passos Alencastro (org.) Projeto político-pedagógico da escola: uma construção possível. 2.ed. Campinas: Papirus, 1996.

e-mail: gisi@aol.com.br 